\section{Self-concept in children with Down syndrome}

\author{
Monica Cuskelly \\ and \\ Inge de Jong
}

\author{
Fred and Eleanor Schonell Special \\ Education Research Centre, \\ University of Queensland
}

\begin{abstract}
There are very few studies which have examined selfconcept in individuals with an intellectual disability and none which have focussed on those with Down syndrome. The study found that children with Down syndrome with a developmental age of 4 to 6 years 11 months have a self-concept which is similar to that of normally developing children of a similar developmental age. The subscale means for both groups were positively skewed, and the subscale scores for both groups of children were found to be reliable over a one week period. Mothers' views of the self-concept of their child with Down syndrome were not correlated with children's own reports.
\end{abstract}

(c) 1993, 1999. The Down Syndrome Educational Trust Down Syndrome Research and Practice

1996, 4 (2) 59-64

\section{Introduction}

In general, research into the self-concept of individuals with intellectual disabilities is very limited and no studies have examined the self-concept of children with Down syndrome. Self-concept is considered to be a predictor of coping with life stresses (Bandura, 1993) and there would appear to be a link between self-concept and academic achievement. See, for example the meta-analysis of studies conducted by Hattie (1992) and the studies by Short (1992) and Chapman (1988).

A barrier to the examination of self-concept with persons with intellectual disability is the lack of instruments designed specifically for use with this group. Two strategies have been adopted to assess self-concept in this population - (1) using scales designed for children with adults with intellectual disabilities (for example, Benson and Ives, 1992), and (2) modifying the administration of existing scales (for example, Zetlin, Heriot and Turner, 1985). The first strategy must be questioned unless it can be shown that the same issues are relevant to both groups and that the basis for the participants' judgements about themselves is also similar. The second strategy also has problems. Zetlin et al. suggested that even with modification to item format, the cognitive demands of the task exceeded the abstraction and generalisation abilities of persons with intellectual disabilities.

As an alternative to standardised measures, semi-structured interviews have been used. Jahoda, Markova, and Cattermole (1988) conducted interviews with twelve adults with intellectual disabilities aged between 21 and 40 years to test the hypothesis that people who are stigmatised by others (eg. those with an intellectual disability) would develop a view of themselves as essentially different from others and would evaluate themselves negatively. The researchers found that, whereas all participants were aware of the stigma attached to them, only three regarded themselves as "essentially different" from people without intellectual disabilities and held a globally handicapped view of themselves.

If self-concept and self-perceptions are regarded as the product of cognitive processes, it could be assumed that the organization of different aspects of self-concept (i.e. its structure and content) would be sensitive to shifts in cognitive development (Silon and Harter, 1985). This would suggest that the structure and content of self-concept of individuals with intellectual disabilities would be more similar to that of mental age comparisons than to that of individuals of similar chronological age. A study by Silon and Harter (1985) provided some support for this hypothesis. One hundred and twenty-six children with an intellectual disability who were between the ages of 9 and 12 years completed the Perceived Competence Scale for Children (Harter, 1982). Factorial analyses revealed a pattern which was dissimilar to the factor solution for children without disabilities matched for chronological age but similar to that for children of pre-school/kindergarten age on a parallel form (Harter and Pike, 1984). When examining perceived physical competence Ulrich and Collier (1990) also found that scores of children with mild intellectual disability were similar to those of younger, normally developing children.

Damon and Hart commented in 1982 that of all the scales in the then current literature "none anticipates or "corrects 
for' developmental transformations in the conception of self ... (or) includes a recognition that the conceptual bases of a subject's self-evaluations may be differently construed and differently weighed at different periods in the subject's development" ( $p$ 842). Harter and her colleagues (Harter, 1982; Harter and Pike, 1984) addressed this complaint by developing a group of instruments for use with children of different ages (4 to 11 years). The instruments are similar in format but attempt to take developmental changes in the content and structure of self-concept into account.

Researchers have suggested that young children typically overestimate their ability, and blur the distinction between their ideal and real selves (Anderson and Adams, 1985; Harter and Pike, 1984; Ulrich and Collier, 1990). Harter (1988) argued that this tendency was not evidence that young children deliberately try to misrepresent themselves or consciously decide to respond in a socially desirable way, but that it reflects the inability of young children to use social comparison. She referred to this inability to make realistic judgements as a normative distortion based on cognitive limitations.

Rubel (1983) investigated the use of social comparison in the self-evaluations of children by giving his subjects feedback on their own performance on difficult tasks and information about the performance of other children their age. The children were then asked for self-evaluations. Rubel found that children younger than seven years made almost no reference to the information about the performances of other children in their evaluations. Rather, they based their evaluations on an "absolute standard" of whether or not they were able to complete the task. Other authors have also reported that children under 7 years of age do not use social comparison information in forming their self-concepts but are focused on absolute physical and behavioural characteristics (Harter, 1983, 1990; Markus and Nurius, 1986; Rosenberg, 1986, Wigfield and Karpathian, 1991).

The inability to use social comparison may be an important factor in the very positive perceptions young children have of their own abilities. This positive skew in self perceptions has also been reported by researchers working with persons with intellectual disability (e.g. Benson and Ives, 1992; Jahoda et al., 1988; Zetlin et al., 1985). Self reports have sometimes been augmented with information collected from parents, or occasionally carers, in studies examining selfconcept in children and individuals with intellectual disability.

Parental views of children's self-concepts: Parental reports of children's self-concepts have been used for two distinct and essentially contradictory purposes: (1) to determine the accuracy of children's ratings and thereby to establish the concurrent validity of self-concept scales and (2) to determine the accuracy of adults' (i.e. parents') predictions of children's self-concepts. Beitchman and Corradini (1988) listed some of the problems of accepting parental views as accurate reflections of their children's self-concept. They suggested that parental reports may be subject to inherent biases such as over-or underreporting of problems, and may also be influenced by attitudes and family interactions.

In an example of the second type of study, Coleman (1984) examined the predictions mothers made of the way their children with learning disabilities (mean age $=9$ years) would respond to items on the Piers-Harris Self-Concept Scale (Piers and Harris, 1969). Mothers' estimates of their children's self-concept were lower than the children's scores. The mothers of normally achieving children, by contrast, overestimated the reports of their children. Both groups of children achieved similar mean self-concept scores. Coleman explained the underrating by the parents of children with learning disabilities in terms of the indirect impact of labelling "as it alters the perception of those who interact with the labelled individual" (p. 216).

This study addressed the question : Do children with Down syndrome who have a mental age of 4 to 6 years have a self-concept that is similar to or different from the self-concept of normally developing children of the same mental age? An additional question related to mothers' ability to predict the way that their children with Down syndrome would respond to questions about their own competence. In order to answer these questions it is, of course, necessary to use an instrument with demonstrated reliability. As no study has established reliability for a self-concept instrument when used with children with Down syndrome this study investigated the test-retest reliability of a self-concept instrument (The Pictorial Scale of Perceived Competence and Social Competence [Harter and Pike, 1984]) in children with Down syndrome with a mental age of 4 to 6 years and in a comparison group matched for mental age across a one week period. Test-retest reliability has not been established for this instrument with children who are developing normally.

\section{Method}

Nineteen adolescents with Down syndrome (6 girls, 13 boys; mean chronological age: 14.2 years) and their mothers participated in this study. Families were recruited from records held at the Schonell Special Education Research Centre, University of Queensland. Initially the records of all adolescents between the ages of 13 and 17 years were examined $(n=46)$. Children who had a developmental age of between 4 and 6 years 11 months $(n=29)$ were selected from this group. For the purposes of this initial identification, developmental age was calculated using the most current data from assessments conducted for an ongoing longitudinal study of the development of children with Down syndrome. Information was available from one of three instruments: The revised edition of the Peabody Picture Vocabulary Test (PPVT-R) (Dunn and Munn, 1981), the Stanford Binet Intelligence Scale - Fourth Edition (Thorndike, Hagen \& Sattler, 1986), and the Stanford Binet Intelligence Scale - Form L-M (Terman and Merrill, 1960). The mean elapsed time since the children's last assessment was 16 months (range 6-24 months). Nine eligible children were excluded as they lived too far away to visit. One child's parents declined to be included in the study as they were experiencing behaviour problems with their daughter. All children with Down syndrome remaining in the sample were assessed with the PPVT-R (Form M) at the beginning of the study to ensure that they still met the mental age selection criterion. One child was excluded from the study as his mental age exceeded that which had been set as a maximum for this study. The final sample size was 18 .

In Queensland, children usually enter school in the year in which they turn 6 , although children born toward the end of the year may enter in the year they turn 7 . Children in preschool are therefore generally between the ages of 4 and 6 vears. Two preschools were approached for 
recruitment of comparison children. The preschools were selected as they were located in the same geographical area as most of the families of the children with Down syndrome in the study. Children in the preschool groups whose parents gave consent for them to be involved and who were present on both testing days ( $43 \%$ of the possible group) were included in the study. The teachers at the preschools were asked to nominate any child in the comparison group about whose development they were concerned. No child was identified as developmentally delayed. Subsequent to the data collection, one child was excluded from the study as it was apparent during administration that he did not understand the task. A comparison group of 20 children ( 6 girls, 14 boys) was obtained.

\section{Instrument}

The Pictorial Scale of Perceived Competence and Social Acceptance (PPCSA) (Harter and Pike, 1984) was designed for children aged between 4 and 7 years. As Harter and her colleagues were unable to find activities that were appropriate across the entire 4 to 7 year range, two forms of the scale were constructed (Harter, 1981). One form was designed for preschool and kindergarten children, and the other for first and second grade children. The preschool/ kindergarten version was used for this study.

Each version of the instrument is made up of four subscales designed to measure perceptions in different domains. The subscales are: Cognitive Competence, Physical Competence, Peer Acceptance, and Maternal Acceptance. Each subscale comprises six items. Each item consists of two pictures placed side by side. The pictures depict children engaging in activities with different levels of competence or social acceptance. Within each subscale pictures of more or less competent/accepted children are counterbalanced so that half of the pictures show the most competent/ accepted children on the right and half show these children on the left of the page. Separate booklets have been designed for use with boys and girls. The only difference between these forms is that the focus children depicted are either boys or girls. When the scale is being administered the child in the pictures is the same sex as the subject. The pictures provide the visual representation of the verbal description provided by the tester and are intended to provide an aid to understanding the items.

The item format used in this scale is designed to reduce children's tendency to give socially desirable responses. The children are presented with each item and read a brief statement about the focus child in the pictures. As the items are read to the children, the examiner points to the appropriate picture. For each item children are first required to choose the picture with the child who is most like them. They are then required to decide whether this child is a lot or a little like them and to indicate their choice by pointing to a large or small circle which is situated below each picture. The examiner points to the circles as the question is asked to facilitate the understanding of the choices. The responses are scored on a four point scale with four being the most competent/accepted and one the least competent/ accepted. The average scores for each subscale provide a profile of perceived competence and social acceptance.

Harter and Pike (1984) provided evidence for the factorial validity of the instrument by using oblique factor analysis of intercorrelations among items. A two-factor solution was revealed with the two competence subscales defining one factor and the two acceptance subscales the second factor. This was true for both the kindergarten/preschool and first/ second grade versions. If children were able to give reasons for their responses this was regarded by Harter and Pike to be an indication of convergent validity. Of the 91 first and second graders tested, $95 \%$ could give reasons for their responses. Only the cognitive and physical subscales were examined in this way.

For a sample of preschool/kindergarten children, internal consistency was found to range from .62 to .87 for the individual subscales (Harter and Pike, 1984). For the total scale, internal consistency was established at .88. When the subscales were combined according to factors, the internal consistency for the competence subscales was .76 and for the acceptance subscales .87. Test-retest reliability was not established by Harter and Pike. Holguin and Sherrill (1990) used the 1st and 2nd grade version of the scale with 30 learning disabled boys (mean age 8.2 years) and found the test-retest reliability on individual subscale scores to range from .76 to .92 . The testing interval was not specified in the report of this study.

\section{Procedure}

Eighteen adolescents with Down syndrome were selected as described above. The PPCSA was administered to each of the children at their homes twice, approximately a week apart (minimum 5 days, maximum 8 day s). The second author conducted all the sessions. The initial session involved administering the PPVT-R (Form M) first. This was generally done in the presence of the mothers. Next, the PPCSA was administered to the child. Mothers were not present during this time. Finally, the PPCSA was presented to the mothers who were asked to respond to each item in the way that they thought their children would have. The examiner used a similar administration procedure to that used when presenting the scale to the children. Mothers were reminded regularly to answer the way they thought their child would have - not should have - answered. Parents were asked not to discuss the session with their children during the coming week. The second session, which involved re-administering the PPCSA to the children, was also conducted at home. Those mothers who wished to see their children's responses to the items were shown the records of both sessions at the completion of the second visit.

The comparison group of children were administered the PPCSA twice with an interval of one week. The sessions took place in the preschools. Both authors were involved in these sessions, and the scale was re-administered to each child by the person who had originally administered it.

\section{Results}

In order to examine the test-retest relaibility of the PPCSA the correlation coefficients between the subscale scores obtained at Time 1 and Time 2 were calculated for both groups. Correlation coefficients were also calculated between the scores on each of the four subscales at Time 1. As this analysis involved multiple correlations, Bonferroni probabilities were calculated. Table 1 provides the correlations between all subscale scores for the group with Down syndrome and Table 2 the correlations for the comparison group. 
Table 1. Correlations between subscale scores for the Down syndrome group.

\begin{tabular}{|l|l|l|l|l|}
\hline & CC1 & PC1 & PA1 & MA1 \\
\hline CC1 & 1.000 & & & \\
\hline PC1 & .660 & 1.000 & & \\
\hline PA1 & $.817^{* * *}$ & $.745^{*}$ & 1.000 & \\
\hline MA1 & .673 & .675 & $.777^{* *}$ & 1.000 \\
\hline CC2 & $.705^{*}$ & .449 & .669 & .648 \\
\hline PC2 & .666 & $.772^{* *}$ & .653 & .586 \\
\hline PA2 & .602 & $.734^{*}$ & $.831^{* *}$ & .707 \\
\hline MA2 & .575 & $.689^{*}$ & $.712^{*}$ & $.765^{* *}$ \\
\hline
\end{tabular}

Note: CC: Cognitive competence

PC: Physical competence

PA: Peer acceptance

MA: Maternal acceptance

1 refers to data collected at time 1

2 refers to data collected at time 2

${ }^{\star}=\mathrm{p}<.05 ;{ }^{* \star} \quad=\mathrm{p}<.01 ;{ }^{\star * *}=\mathrm{p}<.001$

Table 2. Correlations between subscale scores for the comparison group.

\begin{tabular}{|l|l|l|l|l|}
\hline & CC1 & PC1 & PA1 & MA1 \\
\hline CC1 & 1.000 & & & \\
\hline PC1 & .607 & 1.000 & & \\
\hline PA1 & .407 & .399 & 1.000 & \\
\hline MA1 & $.707^{*}$ & .663 & .638 & 1.000 \\
\hline CC2 & .661 & .635 & .480 & .667 \\
\hline PC2 & .467 & $.856^{\star * *}$ & .456 & .493 \\
\hline PA2 & .405 & .297 & $.813^{\star * *}$ & .608 \\
\hline MA2 & .610 & .588 & .568 & $.786^{\star * *}$ \\
\hline
\end{tabular}

Note: CC: Cognitive competence

PC: Physical competence

PA: Peer acceptance

MA: Maternal acceptance

1 refers to data collected at time 1

2 refers to data collected at time 2

${ }^{*}=p<.05 ;{ }^{* *}=p<.01 ;{ }^{* *}=p<.001$

Table 3. Means and standard deviations of subscale scores for the Down syndrome and comparison groups at Time 1 and normative group.

\begin{tabular}{|l|c|c|c|c|c|c|}
\hline \multicolumn{9}{|c|}{ Group } \\
\hline Subscales & \multicolumn{2}{|c|}{$\begin{array}{c}\text { Down Syndrome } \\
(\mathrm{n}=18)\end{array}$} & \multicolumn{2}{c|}{$\begin{array}{c}\text { Comparison } \\
(\mathrm{n}=19)\end{array}$} & \multicolumn{2}{c|}{$\begin{array}{c}\text { Harter and Pike } \\
(1981) \\
(\mathrm{n}=146)\end{array}$} \\
\hline & Mean & SD & Mean & SD & Mean & SD \\
\hline CC & 3.6 & .55 & 3.5 & .46 & 3.5 & .43 \\
\hline PC & 3.6 & .54 & 3.5 & .55 & 3.3 & .43 \\
\hline PA & 3.3 & .43 & 3.2 & .56 & 2.9 & .56 \\
\hline MA & 3.9 & .55 & 3.2 & .61 & 3.0 & .59 \\
\hline
\end{tabular}

Note: CC: Cognitive competence

PC: Physical competence

PA: Peer acceptance

MA: Maternal acceptance
Responses were found to be stable between Time 1 and Time 2 for all the subscales for the group with Down syndrome. The correlations between Time 1 and Time 2 scores for each subscale were significant at or below the .01 level with the exception of the Cognitive Competence subscale for which the correlations were significant at the .05 level. Correlations between Time 1 and Time 2 scores for each subscale for the comparison group were significant at or below the .01 level except for the Cognitive Competence subscale which failed to reach significance ( $p=.057$ ). For both groups, therefore, perceptions of Cognitive Competence were the least reliable.

Different patterns of intercorrelations between subscale scores at Time 1 were found for the Down syndrome and comparison groups. The only significant intercorrelation that was found for the comparison groups was between Cognitive Competence and Maternal Acceptance $(p=.02)$. For the group with Down syndrome, Peer Acceptance subscale scores correlated significantly with all other subscale scores.

A repeated measures MANOVA was used to determine whether a difference existed in the self-concept scores obtained by children with Down syndrome in comparison to children without disabilities, matched for mental age at both Time 1 and Time 2. A significant effect for sex was found for the data collected at Time $1(F,(1,33)=4.603, p<$ .04), however there was no effect for group and no significant interaction. No main or interaction effects were found for group or sex at Time 2. Boys' scores were significantly higher than girls' scores for both the Cognitive Competence subscale and the Peer Acceptance subscale at Time 1 $p<$ $.02, p<.01$ respectively). The means for the Cognitive Competence subscale were $M=3.27$ for the total sample of girls, and $M=3.71$ for the total sample of boys. For the Peer Acceptance subscale they were $M=2.94$ for the total sample of girls, and $\mathrm{M}=3.40$ for the total sample of boys.

In addition to examination of the data sets taken on the two separate occasions, the data was also compared across the two occasions using repeated measures MANOVA. Each subscale was examined separately. An effect for sex was found for the Cognitive Competence subscale only $(F(1,33)=4.581, p<.04)$. Girls increased their score on this subscale over time and boys' scores were lowered.

There was no effect for group and no significant interaction.

The means, standard deviations and ranges of scores on each sub-score for the Down syndrome and comparison groups at the time of first testing are provided in Table 3 . The means and standard deviations for the sub-scores reported by Harter and Pike (1984) are included in this table as additional information. Inspection of the means and standard deviations show very similar scores for the comparison group and Harter and Pike's sample. This provides tentative support for the use of the means established by Harter and Pike with Australian children. The subscale means for both groups used in this study were positively skewed. 
Correlations between the maternal reports of the selfperceptions of their children with Down syndrome and the reports obtained from the children were calculated. The scores obtained by the children during the first testing session were used in this calculation. Pearson correlation coefficients were all nonsignificant and ranged from .205 to .454 .

\section{Discussion}

The subscale scores on the Peer Acceptance, Maternal Acceptance and Physical Competence subscales for both the Down syndrome and comparison groups were found to be highly correlated between the two data collection sessions. For both groups, the Cognitive Competence subscale scores were the least stable. This may either indicate something about the usefulness of the scale as an indicator of perceived cognitive competence, or may indicate something about the way children at this chronological and mental age perceive cognitive competence.

An interesting difference was found between the groups on the examination of the intercorrelations between subscales. Peer Acceptance scores were found to correlate significantly with all other subscales recorded during the first testing session for the group with Down syndrome. This was not the case for the comparison group; nor was this found by Harter and Pike (1984). Further research is needed to examine the importance of perceived peer acceptance in the structure of self-concept in children with Down syndrome. Most mothers reported that they were concerned about their children's peer relationships and were particularly interested in examining their children's responses on the Peer Acceptance subscale. The report of an ethnographic study of adolescent girls with intellectual disabilities included the concern expressed by staff at special schools and parents of children with intellectual disabilities that the girls had few friends and experienced difficulties forming friendships (Gunn and Bramley, 1989).

No significant differences were found between the scores obtained by the children with Down syndrome and the comparison children on the subscales of the PPCSA. The results of this study may be taken as a tentative indication that children with Down syndrome with a mental age comparable to that of normally developing children in preschool use similar cognitive processes in forming selfconcept as do these comparison children. As the instrument used does not assess the processes but rather the products or manifestations of self-concept formation, this speculation must be regarded with caution. When the products of cognitive processes are alike, one may not assume that the processes used to arrive at them are necessarily similar.

Both groups in this study had means which were positively skewed for all four subscales. Other researchers have similarly found that young children typically judge their competence and acceptance positively (Anderson and Adams, 1985; Harter and Pike, 1984; Ulrich and Collier, 1990). Harter (1988) argued that these findings indicate children's inability to make realistic judgements. She described this as a normative distortion based in young children's inability to make social comparisons.

A main effect for sex was found at Time 1, with boys' responses being more positive on the Cognitive Competence and Peer Acceptance subscales. At Time 2 girls' scores on the Cognitive Competence subscale were higher than at Time 1 and boys' were lower. As Cognitive Competence was not a particulalry reliable scale these findings should be treated with caution.

Even though the sample size for this study was small (37 as opposed to 146 for Harter and Pike 1984), the means and standard deviations for the comparison group were similar to those found by Harter and Pike. This provides some support for the use of the norms obtained by Harter and Pike with children in Australia. However, the patterns of intercorrelations found for either of the groups did not fit the expectation, based on Harter and Pike's findings, that the Competence subscales and Acceptance subscales would be most highly correlated. Harter and Pike did find, however, that the factor loadings and intercorrelations in their preschool/kindergarten group were less significant than those found for the older children. The researchers explained this finding in terms of self-concept being less well differentiated in younger children.

The correlation between maternal reports and reports by children with Down syndrome were not significant. Due to a number of potential limitations of self-report measures, it has been suggested that maternal reports and observations may be useful in assessing the self-concept of children with intellectual disabilities and in providing concurrent validity for scales of self-concept (Beitchman and Corradini, 1988; Damon and Hart, 1982; Harter, 1981; Wigfield and Karpathian, 1991). The problems with self-report scales for this population include difficulties with understanding the vocabulary and response formats, reading difficulties, and the cognitive ability to evaluate feelings and attitudes. However, the validity of using the reports of significant others for the purposes of providing concurrent validity or an insight into children's self-concepts can be questioned, as it is the child's perceptions that are of interest rather than the interpretations made by others from the children's behaviours or the accuracy of children's perceptions.

Mothers of children with Down syndrome were asked to respond to the test items in the way that they thought their children would have. Frequent comments were made by mothers that indicated that they found this task difficult and they often lapsed into providing answers that reflected the way they thought about their children's competence and acceptance. Most mothers also commented that they generally found it very difficult to know how their children interpreted experiences and most were eager to see their child's responses. Mothers spontaneously provided examples of their children's experiences as they were thinking about or trying to "work out" the reasoning their children may have used when responding to individual items. Peer acceptance was of particular concern to these parents.

Once the children's responses were shown to the mothers, a few mentioned that they could think of examples that had demonstrated their children's positive self-judgements. A few gave explanations for why they believed their children had responded as they had. "She really does not have any friends she will stay at overnight, but she visits her older sisters/aunts and uncles from time to time... She probably counts all these people as friends." "We ask him who the fastest runner or the best soccer player in the world is and he always says: 'Me'" "She can make knots in her shoelaces. To her, being able to tie them at all means that 
she can tie them well."

When questioned whether they thought that their children may be providing positive responses in order to impress, mothers consistently said that they did not think their children were doing this, but that they were confusing what they would like with the way things were.

The study found tentative support for the idea that children with Down syndrome with a developmental age of 4 to 6 years 11 months use similar cognitive processes to normally developing children of a similar developmental age in deriving their self-concept. Support for this view comes from the findings that no significant differences were found on the self-concept profiles of the PPCSA, the subscale means for both groups were positively skewed, and that the subscale scores for both groups of children were found to be reliable over a one week period. Due to the small sample size of this study, however, results must be viewed with caution. In addition, the study has highlighted a number of questions which remain to be investigated, for example the differences in intercorrelations between sub-scores found for the two groups, the key importance of peer acceptance in children with Down syndrome, possible gender differences, the influence of recent experience, and the use of social comparison information in the self-perceptions of these children.

\section{References}

Anderson,P.L. and Adams,P.J. (1985). The relationship of five-year-olds' academic readiness and perceptions of competence and acceptance. Journal of Educational Research, 79, 114-118.

Bandura,A. (1993). Perceived self-efficacy in cognitive development and functioning. Educational Psychologist, 28, 117-148.

Beitchman,H. and Corradini,A. (1988). Self-report measures for use with children: A review and comment. Journal of Child Psychology, 44, 477-490.

Benson,B.A. and Ives,J. (1992). Anger, depression and self-concept in adults with mental retardation. Journal of Intellectual Disability Research, 36, 169-175.

Chapman,J.W. (1988). Learning disabled children's selfconcepts. Review of Educational Research, 58, 347-371.

Coleman,J.M. (1984). Mothers' predictions of the selfconcept of their normal or learning disabled children. Journal of Learning Disabilities, 17, 214-217

Damon,W. and Hart,D. (1982). The development of selfunderstanding from infancy through adolescence. Child Development, 53, 841-864.

Dunn,L.M. and Munn,L.M. (1981). Peabody Picture Vocabulary Test - Revised. Circle Pines, Minn: American Guidance Service.

Gunn,P. and Bramley,J. (1989). Personal development. In P. Gunn \& J. Bramley (Eds), Adolescent girls with intellectual disabilities: School and post-school options. Fred and Eleanor Schonell Special Education Research Centre. University of Queensland.

Harter,S. (1981). A model of mastery motivation in children: Individual differences and developmental change. Minnesota symposium on child psychology, 14, 215-255.

Harter,S. (1982). The Perceiced Competence Scale for Children. Child Development, 53, 87-97.

Harter,S. (1983). The development of the self-system. In M. Hetherington (Ed.), Handbook of child psychology: Social and personality development, pp277-358. New York: Wiley.
Harter,S. (1988). Developmental and dynamic changes in the nature of the self-concept: Implications for child psychotherapy. In S.R. Shirk (Ed.) Cognitive development and child psychotherapy, pp119-160. New York: Plenum Press.

Harter,S. (1990). Selfhood processes and the emotional disorders. Cognitive Therapy and Research, 14, 112-142.

Harter,S. and Pike,R. (1984). The Pictorial Scale of Perceived Competence and Social Acceptance for Young Children. Child Development, 55, 1969-1986.

Hattie,J. (1992). Self-concept. Hillsdale: Lawrence Erlbaum Associated.

Holguin,O. and Sherrill,C. (1990). Use of Pictorial Scale of Perceived Competence and Acceptance with learning disabled boys. Perceptual and Motor Skills, 70, 1235-1238. Jahoda,A., Markova,I. and Cattermole,M. (1988). Stigma and self-concept of people with mild mental handicap. Journal of Mental Deficiency Research, 32, 103-115.

Marcus, H. and Nurius, P. (1986). Possible selves. American Psychologist, 41, 954-969.

Piers, E.V. and Harris, D.B. (1969).The Piers-Harris Children's Self-Concept Scale. Nashville, Tenn: Counsellor Recording and Tests.

Rosenberg,M. (1986). Self-concept from middle childhood through adolescence. In J. Suls \& A.G. Greenwald Eds), Psychologocal perspectives on the self (Vol 3), pp107-136. Hillsdale NJ: Lawrence Erlbaum Associates, Inc.

Rubel, D. (1983). The development of the social comparison processes and their role in achievement-related selfsocialisation. In E.T. Higgins, D.N. Rubel, \& W.W. Hartup (Eds), Social cognition and social development: $A$ sociocultural perspective, pp134-157. New York: Cambridge University Press.

Short, E.J. (1992). Cognitive, metacognitive, motivational, and affective differences among normally achieving, learning disabled, and developmentally handicapped students: How much do they affect school achievement? Journal of Clinical Child Psychology, 21, 229-239.

Silon,E.L., and Harter, S. (1985). Assessment of perceived competence, motivational orientation, and anxiety in segregated and mainstreamed educable mentally retarded children. Journal of Educational Psychology, 77, 217-230.

Terman,L.M. and Merrill,M.A. (1960). Stanford-Binet Intelligence Scale. Boston: Houghton Mifflin.

Thorndike, R.L., Hagen, E.P. and Sattler, J.M. (1986). Stanford-Binet Intelligence Scale - Fourth Edition. Chicago: Riverside Publishing.

Ulrich,D.A. and Collier,D.H. (1990). Perceived physical competence in children with mental retardation: Modification of a pictorial scale. Adapted Physical Activity Quarterly, 7, 338-350.

Wigfield,A. and Karpathian,M. (1991). Who am I what can I do: Children's self-concepts and motivation in achievement situations. Educational Psychologist, 25, 233-261.

Zetlin, A.G., Heriot, M.J. and Turner, P. (1985). Self-concept measurement in mentally retarded adults: A micro-analysis of response styles. Applied Research in Mental Retardation, 6, 113-125.

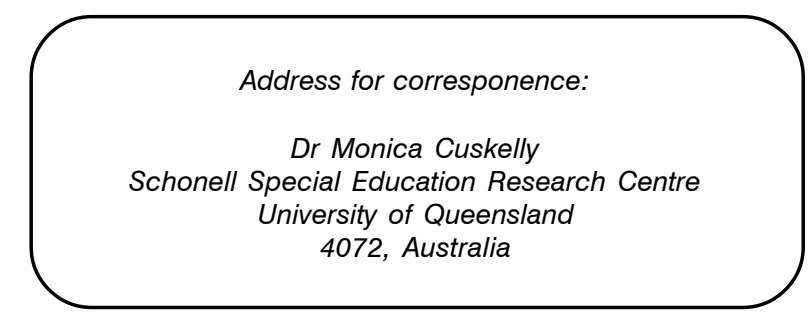

